\title{
Using High-Resolution Altimetry to Observe Mesoscale Signals
}

\author{
M.-I. Pujol AND G. Dibarboure \\ CLS, Toulouse, France \\ P.-Y. LE TRAON AND P. KLEIN \\ IFREMER, Brest, France
}

(Manuscript received 17 February 2012, in final form 6 April 2012)

\begin{abstract}
An Ocean System Simulation Experiment is used to quantify the observing capability of the Surface Water and Ocean Topography (SWOT) mission and its contribution to higher-quality reconstructed sea level anomaly (SLA) fields using optimal interpolation. The paper focuses on the potential of SWOT for mesoscale observation (wavelengths larger than $100 \mathrm{~km}$ and time periods larger than 10 days) and its ability to replace or complement altimetry for classical mesoscale applications. For mesoscale variability, the wide swath from SWOT provides an unprecedented sampling capability. SWOT alone would enable the regional surface signal reconstruction as precisely as a four-altimeter constellation would, in regions where temporal sampling is optimum. For some specifics latitudes, where swath sampling is degraded, SWOT capabilities are reduced and show performances equivalent to the historical two-altimeter constellation. In this case, merging SWOT with the two-altimeter constellation stabilizes the global sampling and fully compensates the swath time sampling limitations. Benefits of SWOT measurement are more important within the swath. It would allow a precise local reconstruction of mesoscale structures. Errors of surface signal reconstruction within the swath represent less than $1 \%$ (SLA) to 5\% (geostrophic velocities reconstruction) of the signal variance in a pessimistic roll error reduction. The errors are slightly reduced by merging swath measurements with the conventional nadir measurements.
\end{abstract}

\section{Introduction}

During the past 20 years, altimeter sea surface height ( $\mathrm{SSH}$ ) measurements have made major contributions to the understanding of the ocean circulation and its variability. While 1D along-track SSH data can observe wavelengths as small as $30-50 \mathrm{~km}$ (with a measurement noise of about $2 \mathrm{~cm} \mathrm{rms}$ ), global mesoscale resolution is mainly limited by the large gaps between SSH profiles from altimetry and by the revisit time of each altimeter (e.g., Le Traon and Dibarboure 1999; Le Traon et al. 2001; Tai 2006).

The necessity to accurately observe small-scale signals as $2 \mathrm{D}$ images had led to the development of the wideswath interferometry technique (Fu and Rodriguez 2004; Alsdorf et al. 2007), which resulted in the Surface Water and Ocean Topography (SWOT) mission recommended

Corresponding author address: M.-I. Pujol, CLS-DOS, 8-10 rue Hermes, Parc Technologique du canal, 31520 Ramonville SaintAgne, France.

E-mail: mpujol@cls.fr by the National Research Council's "decadal survey." A detailed description of the SWOT mission is given by Rodríguez (2010) and Durand et al. (2010). SWOT is designed to measure the height of inland water surfaces and the ocean and should be implemented in the coming decade. The surface topography measurement would be based on both a nadir altimeter and a Ka-band radar interferometer (KaRIN). With a nearly 120-km-wide swath, its spatial coverage will be nearly global, repeating every 21 days. Only latitudes larger than $78^{\circ}$ and small gaps around the equator would not be entirely sampled. The main originality of SWOT over ocean will be its capability to sample submesoscale signal. SWOT should measure ocean surface topography with a height precision of a few centimeters over areas of less than $1 \mathrm{~km}^{2}$, that is 5 times as stringent as the accuracy observed on Jason-class pulselimited altimeters. Because mesoscale features have an amplitude that is globally decreasing with wavenumber (Le Traon et al. 2008), SWOT's capability to observe mesoscale and submesoscale signals will strongly depend on the level of measurement errors. 
TABLE 1. Principal characteristics of the different missions used.

\begin{tabular}{|c|c|c|c|c|}
\hline Mission & Jason-2 & Envisat & $G F O$ & SWOT \\
\hline Repeat cycle (days) & 10 & 35 & 17 & 22 \\
\hline $\begin{array}{l}\text { Cross-track distance at the } \\
\text { equator }(\mathrm{km})\end{array}$ & $\sim 315$ & $\sim 80$ & $\sim 165$ & $\sim 0$ \\
\hline Along-track resolution & $7 \mathrm{~km}(1 \mathrm{~Hz})$ & $7 \mathrm{~km}(1 \mathrm{~Hz})$ & 7 km (1 Hz) & $7 \mathrm{~km} \times 5 \mathrm{~km}$ \\
\hline White noise & & $2 \mathrm{~cm} \mathrm{rms}$ & & $\begin{array}{l}\text { Cross-swath varying: } \\
\min =0.14 \mathrm{~cm} \mathrm{rms} \\
\max =0.35 \mathrm{~cm} \mathrm{rms}\end{array}$ \\
\hline Roll error & & - & & $\begin{array}{l}\text { Optimistic: } 0.05 \operatorname{arc~s} \\
\text { Pessimistic: } 0.1 \operatorname{arc~s}\end{array}$ \\
\hline
\end{tabular}

Various studies previously focused on mesoscale mapping capabilities of single- or multiple-altimeter missions. All of them address conventional nadir altimeter measurement. With the aim of quantifying the capability of existing constellations (e.g., Le Traon and Dibarboure 1999; Ducet et al. 2000; Pujol and Larnicol 2005; Dibarboure et al. 2011) or the impact of a future mission or potential orbit change scenario (e.g., Smith and Scharroo 2009; Dibarboure et al. 2012b), they showed that at least two altimeters are required to accurately reconstruct the global ocean surface topography at a mesoscale resolution (i.e., scales larger than $100-150 \mathrm{~km}$ and 10-15 days). Specific studies, however, highlighted the impact of near-real-time (NRT) versus delayed-time conditions. In NRT up to four altimeters need to be merged for an accurate reconstruction of mesoscale signals (Pascual et al. 2006, 2009). In addition, there is an important sensitivity of NRT mesoscale sampling to the synchronization and phasing of the constellation considered. This is well illustrated with the results obtained with Jason-1/Ocean Topography Experiment (TOPEX) and Jason-2/Jason-1 tandem missions (Dibarboure et al. 2011). The 5-day shift between Jason-1 and Jason-2 makes possible a more efficient NRT observation of mesoscale signal when compared with the TOPEX-tandem/Jason-1 constellation.

In this paper, we quantify for the first time the potential of SWOT for a continuous space/time monitoring of ocean surface topography signals. We specifically focus on mesoscale signal, which until now has been reconstructed by using conventional nadir constellation measurements. With the swath sampling and a local temporal repeat cycle of nearly 3 days (combining ascending and descending orbits), SWOT indeed presents an unprecedented potential for the observation of mesoscale signals and surface gradients. Multimission sampling assessments (e.g., Le Traon et al. 2003) are revisited with SWOT, using an optimal interpolation (or objective analysis) method to reconstruct topography signals between SWOT images. Note that the observation of submesoscale signals that is one of the scientific objectives of SWOT is not addressed in this paper. The aim of this paper is indeed to assess SWOT's ability to replace or to complement altimetry for mesoscale applications. Potential of SWOT measurement for submesoscale signal reconstruction should be addressed in a dedicated study.

The paper is organized as follows. The data and methods used are presented in section 2 . In section 3 , we analyze the errors on mesoscale reconstruction. Mesoscale signals are defined as the smallest scales observed so far with conventional nadir altimetry. A summary and conclusions on the results obtained are given in section 4 .

\section{Data and methods}

The analysis presented in this paper is based on an Ocean System Simulation Experiment (OSSE) for altimeter gridded product construction. The method is derived from Le Traon et al. (2001) and Le Traon and Dibarboure (2002). The approach is the same as the one used by the previous authors but with different reference fields, different sensors, and shorter scales.

\section{a. Constellations considered}

Different altimeter combinations were considered in this paper. Some configurations are based on the merging of two or four historical altimeter missions, as is commonly done with real data (Dibarboure et al. 2011). The historical two-satellite combination (J2EN) is based on Jason-2 (J2), which follows an orbit to be used for Jason-3 and likely for Jason-Continuity of Service (CS), and its successors as well, and Environmental Satellite (Envisat; EN), to be used for the Satellite with Argos and AltiKa (Ka-band radar altimeter and radiometer), or Saral. The four-satellite configuration (J2ENG2J1N) also includes interleaved Jason-1 (J1N) and Geosat Follow-On (GFO; G2).

Two other configurations are analyzed. They are based on SWOT's wide-swath sampling on a 22-day repeat orbit (S22). SWOT is first simulated alone (i.e, S22), and then it is combined with two historical satellites (Jason-2 and Envisat; S22J2EN). The main characteristics of each mission are summarized in Table 1. 


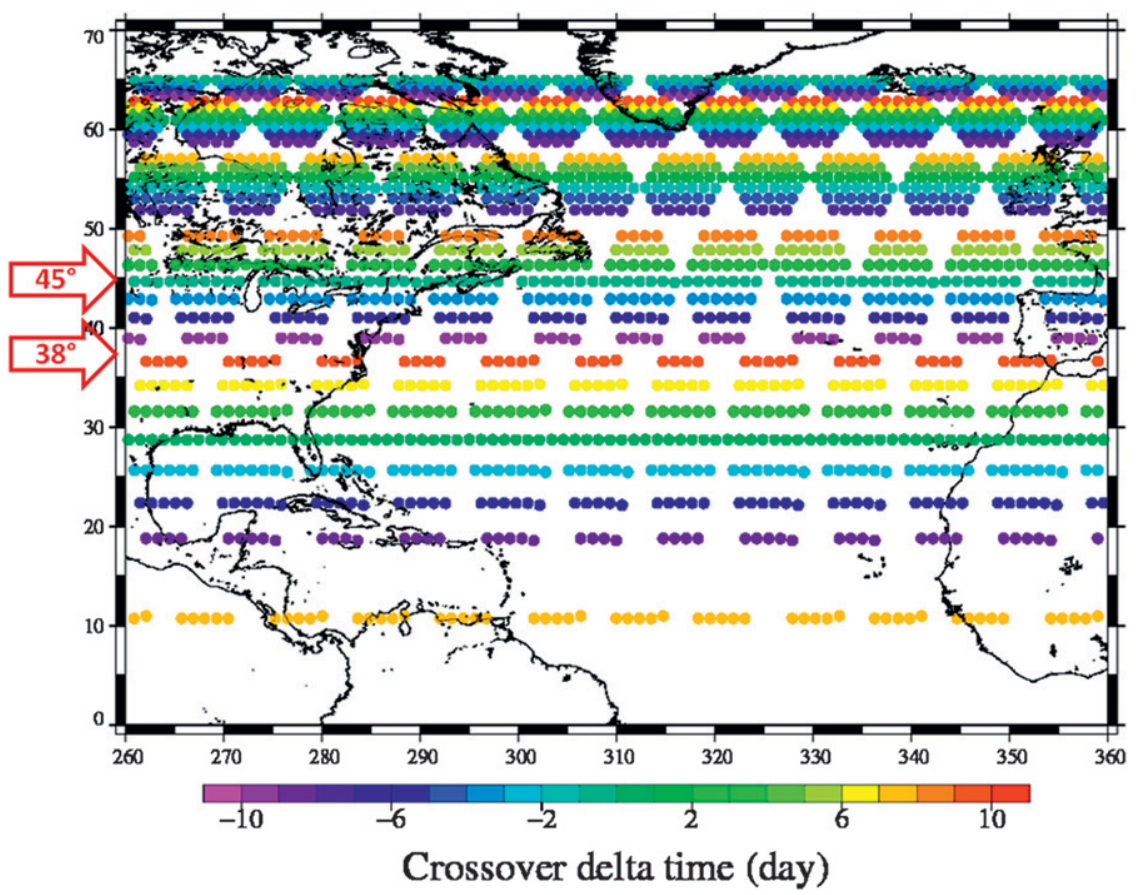

FIG. 1. SWOT crossover delta time (days), that is, the temporal difference between the ascending and descending arcs. The coverage is limited to crossovers with a $\delta T$ of less than 10 days.

\section{b. Model outputs used as reference field}

$\mathrm{SSH}$ used as reference field in this study is derived from the Earth Simulator (ES) model of Klein et al. $(2008,2009)$. The model simulates mesoscale variability, with typical scales ranging from 10 to $300 \mathrm{~km}$. SSH model output was used with a resolution of 1 day and $2 \mathrm{~km} \times 2 \mathrm{~km}$. The maximum signal variability is located in the center of the domain, where it ranges from 15 to $30 \mathrm{~cm} \mathrm{rms}$, with $10 \%-25 \%$ of the $\mathrm{SSH}$ variability induced by short wavelength signals (wavelengths smaller than $100 \mathrm{~km}$ ). The ES simulation used in this study is relevant for midlatitudes because the resulting mesoscale eddy field and sea level variability are generic in terms of the characteristics of high-eddy kinetic areas located at these latitudes (see Klein et al. 2008). The ES simulation is idealized and is therefore not georeferenced. For this study, the area was arbitrarily set in the Pacific Ocean. Two latitudes were considered and derived from observations from Dibarboure et al. (2012a). The first set of simulations was positioned around $38^{\circ} \mathrm{N}$, corresponding to a zone of optimal temporal sampling of the S22 orbit: ascending and descending passes are separated by about 10-11 days out of a 22 -day cycle (Fig. 1). The second set of simulations was positioned around $45^{\circ} \mathrm{N}$ to study the case of degraded sampling.
The ascending and descending SWOT swaths are within 2-3 days, and no other data are available over the 22-day time period. Both latitudes considered are characteristic of intense mesoscale activity areas that are already observed with conventional nadir altimeters (e.g., Gulf Stream, Kuroshio, and Agulhas Current).

\section{c. Simulated observations}

The geometry of the nadir altimetry tracks and the SWOT swath was simulated, and then a trilinear interpolation was used to generate error-free sea level anomaly (SLA) measurements from each satellite. The classical $1 \mathrm{~Hz}$ (i.e., 6-7 km) along-track resolution was used for nadir satellites. In the SWOT swath a $5 \mathrm{~km} \times$ $7 \mathrm{~km}$ sampling resolution was used. This was chosen rather than the full $1-\mathrm{km}$ resolution expected from ocean SWOT products to reduce the computational workload. Measurement errors were, however, adjusted accordingly (see below), and our results should thus be equivalent to those derived from the fullresolution dataset. Different measurement errors were added to the ideal SLA measurements:

1) Nadir altimeters-The $2-\mathrm{cm}$ rms white noise was used as a compromise between the current noise level observed on level-2 altimetry products $(3 \mathrm{~cm})$ 
observed by Thibaut et al. (2009b) and the improved nadir technology or processing that will be available by SWOT's launch $(1 \mathrm{~cm}$; Thibaut et al. 2009a; Ollivier 2006).

2) SWOT (noise)—White-noise levels were assigned a varying amplitude in the across-track direction position, in accordance with satellite design requirements (Durand et al. 2010; E. Rodriguez 2011, personal communication). With $7 \mathrm{~km} \times 5 \mathrm{~km}$ spatial resolution, noise ranges from near $0.2 \mathrm{~cm}$ rms in the inner part of the swath to near $0.35 \mathrm{~cm}$ rms on the outer edges of the swath.

3) SWOT (roll)—Residual roll errors were added as if SWOT data were preprocessed with empirical roll error mitigation techniques on the basis of multisatellite data (e.g., Dibarboure et al. 2012a). The optimistic case corresponds to a residual error of 0.05 arc s (i.e., maximum variability of the oscillations $<2 \mathrm{~cm}$ rms at the extremity of the swath). The pessimistic case corresponds to a residual error of 0.1 arc s. In both cases, the roll error is assumed to affect only long wavelengths (of $500 \mathrm{~km}$ or more).

\section{d. Reconstructed ocean topography}

The optimal interpolation (OI) derived from Le Traon et al. (1998) was used to reconstruct SLA fields on a $1 / 8^{\circ} \times 1 / 8^{\circ}$ grid every 3 days over a 1 -yr period. The main characteristics of the OI method are given in the appendix. Surface velocity anomalies are directly deduced from the SLA field using the geostrophic approximation. The input parameters used by the OI are the covariance error matrices given to each dataset and the spatial and temporal scales that provide a statistical description of the signal to reconstruct (see the appendix).

The OI specifically accounts for the white noise present in each dataset and described in section 2c. No specific parameterization was implemented to account for residual roll errors added to SWOT data, however. Although the correlation could be properly modeled in the OI error covariance matrices (e.g., Le Traon et al. 1998), this complex improvement was not done, mainly because the roll error was already assumed to be minimized through similar empirical techniques.

We focus on mesoscale structures with typical correlation scales of $100 \mathrm{~km}$ and 10 days. These correlation scales, given as input to the OI process, were chosen as a compromise between characteristic scales of the signal to be reconstructed and conventional nadir constellation sampling limits (Ducet et al. 2000; Pujol et al. 2005).

The errors of reconstructed fields derived from OI are estimated by analyzing the variance of the difference between the true model output and the "reconstructed" quantities. The differences thus provide insights into the sum of two categories of errors: the first category includes processing and mapping errors (e.g., bad parameterizations or crude approximations), and the second category comprises measurement error and sampling capability limitations of the observing system. The first category is minimized by using a simple OI process with adequate parameters and that is based on observations only (as opposed to model OSSEs, for which assimilation errors or model discrepancies between the "true model" and the "reconstructed model" could be more substantial). The second category of errors largely dominates because we do not have sufficient data to resolve the smallest scales with observations only (spatially, temporally, or both).

The correlation scales used here do not allow us to fully resolve submesoscale signals that are present in the ES reference field. For this reason, the errors on reconstructed fields were analyzed by considering only the long-wavelength fraction of the reference signal, using a 2D Loess filter with a $100-\mathrm{km}$ cutoff wavelength (Schlax and Chelton 1992). The errors are expressed in percent of variance of the reference signal.

\section{Mesoscale signal reconstruction}

SWOT contribution to mesoscale signal reconstruction is analyzed within the swath only and at regional scales. The first configuration allows us to characterize the swath capability for local mesoscale observation, without taking into account limitations induced by spatial and temporal sampling. It also underlines the impact of swath-specific errors, such as roll error, and the benefits of merging the swath measurement with conventional nadir measurement for reducing the errors. The regional analysis (i.e., within and out of the swath) was performed to estimate the impact of SWOT sampling for traditional altimetry applications at regional scale and to compare it with the capabilities of the historical nadir constellations. Benefits of merging the swath measurement with conventional nadir measurement are also analyzed.

\section{a. Observation error within the SWOT swath}

As expected from a precise 2D SSH imager, the sampling errors observed using SWOT, alone or combined with other satellites, are substantially lower than with nadir altimeter constellations (Table 2). Whereas conventional altimetry still has an error of $9 \%$ for mesoscale SLA fields, errors for SWOT alone are one-third as large as errors in four-satellite nadir configurations and one-ninth as large as in two-satellite configurations. 
TABLE 2. SLA, $U, V$, and vorticity mapping errors (in percent of signal variance). Results are computed in the SWOT swaths only.

\begin{tabular}{lccc}
\hline \hline & $\begin{array}{c}\text { Jason-2 }+ \\
\text { Envisat }\end{array}$ & $\begin{array}{c}\text { Jason-1 }+ \\
\text { Envisat }+ \text { GFO }\end{array}$ & SWOT \\
\hline SLA & 9 & 3 & 1 \\
$U$ & 13 & 5 & 2 \\
$V$ & 23 & 9 & 4 \\
Vorticity & 27 & 13 & 5 \\
\hline
\end{tabular}

A significant ratio is also observed for geostrophic velocity and vorticity fields: nadir configurations still exhibit errors that can reach $27 \%$ (vorticity), whereas in the SWOT swath errors are of 5\%. Although measurement errors are affected by simulated noise and correlated errors (i.e., small scales that cannot be reconstructed with OI), OI provides very good estimates of mesoscale (100 km and 10 days) velocity and vorticity fields.

Differences are observed between zonal and meridional velocities. For historical nadir constellations, these are mainly induced by the spatial sampling of the different satellites. The orbit inclination and the intertrack distance favor zonal velocity sampling. In the case of SWOT simulations, the same anisotropy is observed even though the input measurements are 2D images and the estimation is limited to the swath itself. In this case, the anisotropy is mainly induced by the residual roll errors simulated in the input data as discussed in section $3 \mathrm{c}$.

\section{b. Mean observation error}

The reconstruction error observed on a regional average (in and out of SWOT's swath) is latitude dependent (Dibarboure et al. 2012a). For instance, the latitude band at $38^{\circ}$ corresponds to a zone of optimal temporal sampling of the SWOT orbit (Fig. 1): ascending and descending passes are separated by about 10-11 days out of a 22-day cycle. Consequently the reconstruction error is substantially lower at this latitude. Conversely, the latitude band of $45^{\circ}$ is a case of degraded sampling; the two SWOT images are within 2-3 days and then no data are available over the cycle duration. Consequently, the reconstruction errors are larger.

Figure 2 shows the average formal mapping error over a 1-yr period using SWOT or conventional nadir

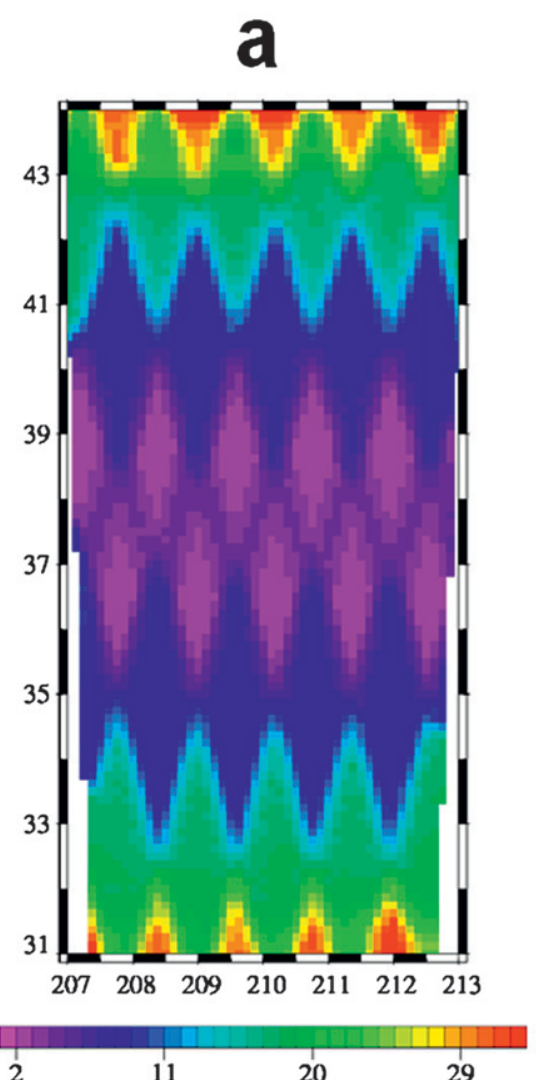

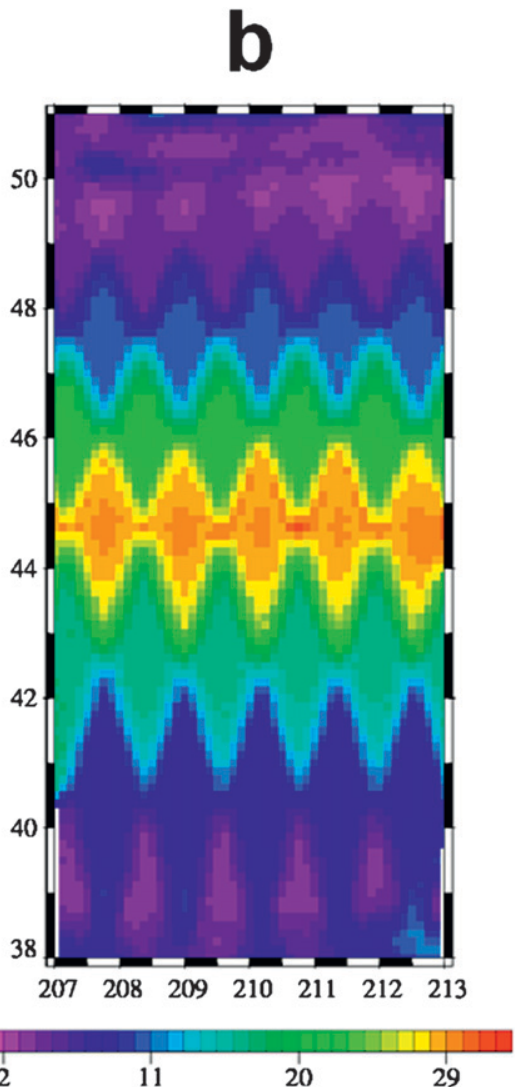

11

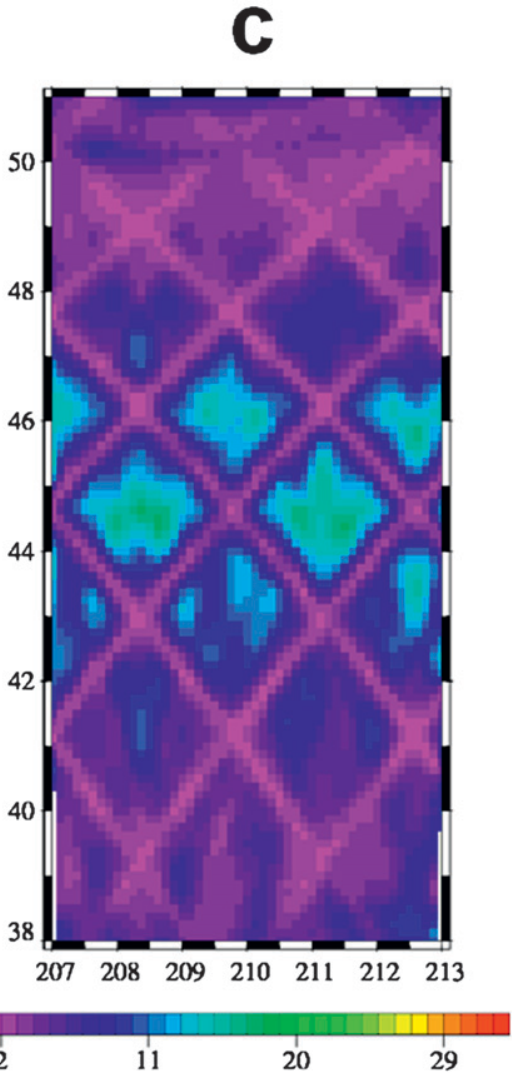

11

FIG. 2. Formal mapping error (in percent of signal variance) for S22 at (a) $38^{\circ} \mathrm{N}$ and (b) $45^{\circ} \mathrm{N}$ and for (c) S22J2EN at $45^{\circ} \mathrm{N}$. Measurement errors are not simulated or taken into account in this figure. 
TABLE 3. SLA, $U, V$, and vorticity mapping errors (in percent of signal variance). Results are shown for simulations centered on $38^{\circ} \mathrm{N}$ (boldface) and for simulations centered on $45^{\circ} \mathrm{N}$ (in parentheses). Results are computed regionally, that is, in and out of the SWOT swaths.

\begin{tabular}{|c|c|c|c|c|}
\hline & $\begin{array}{c}\text { Jason-2 }+ \\
\text { Envisat }\end{array}$ & $\begin{array}{c}\text { Jason-2 }+ \\
\text { Jason-1 }+ \\
\text { Envisat }+ \text { GFO }\end{array}$ & SWOT & $\begin{array}{r}\text { SWOT + } \\
\text { Jason }+ \\
\text { Envisat }\end{array}$ \\
\hline SLA & $9(8)$ & $3(3)$ & 3 (11) & $2(3)$ \\
\hline$U$ & 13 (11) & $5(5)$ & $5(14)$ & $3(5)$ \\
\hline$V$ & $23(22)$ & $9(9)$ & $7(21)$ & $5(10)$ \\
\hline Vorticity & 27 (27) & $13(14)$ & $11(28)$ & $8(14)$ \\
\hline
\end{tabular}

altimetry. The formal mapping error represents a purely theoretical mapping error. It mainly traduces errors induced by the constellation sampling capability and consistency with the spatial/temporal scales considered, as described in Le Traon et al. (1998) or Ducet et al. (2000). When the simulation and reconstruction are performed around $38^{\circ}$, the mean formal error is lower than $5 \%-10 \%$ in the central part of the area where higher variability of the signal is observed. When the exact same reconstruction is performed around $45^{\circ}$, however, the average formal mapping error is larger than $20 \%-25 \%$ of the signal variance. This can be compared with the results obtained with a two-nadir-altimeter constellation $(10 \%-$ 15\%; Le Traon and Dibarboure 1999; Ducet et al. 2000). The SWOT temporal sampling is thus not sufficient for the OI to perform a good reconstruction.

Table 3 summarizes these results. The observed errors of reconstructed fields increase by a factor of 3 from $38^{\circ}$ (best SWOT temporal sampling) to $45^{\circ}$ (worst SWOT temporal sampling). Mapping errors with SWOT alone are comparable to mapping errors of a four-satellite configuration at $38^{\circ}$ with $3 \%$ on SLA, $5 \%$ on zonal velocity $U, 7 \%$ on meridional velocity $V$, and $11 \%$ on vorticity and to observations of a two-satellite configuration at $45^{\circ}$ with $11 \%$ on SLA, $14 \%$ on the $U$ field, and $21 \%$ on the $V$ field. The sampling capability of a single satellite, albeit with a large swath, is limited by the orbit characteristics and displays large discrepancies with latitude.

Combining SWOT with two nadir altimeters provides a strong reduction of this spatial heterogeneity of the topography sampling, as shown by Table 3 (right column). While adding two nadir altimeters does reduce the error in general, the improvement is much larger around $45^{\circ}\left(3 \%\right.$ vs $11 \%$ on SLA) than around $38^{\circ}(2 \%$ vs $3 \%)$. The reconstruction errors observed when SWOT is merged with two nadir altimeters are spatially more homogeneous: the error increase from $38^{\circ}$ to $45^{\circ}$ is $30 \%-$ $100 \%$ as opposed to the factor of $300 \%$ observed with SWOT alone. The average regional performance of the
TABLE 4. SLA, $U, V$, and vorticity mapping errors (in percent of signal variance). Results are shown for simulations centered on $38^{\circ} \mathrm{N}$, when pessimistic (boldface) and optimistic (parentheses) roll errors are considered. Results are computed in the SWOT swaths.

\begin{tabular}{lcr}
\hline \hline & SWOT & $\begin{array}{c}\text { SWOT + Jason + } \\
\text { Envisat }\end{array}$ \\
\hline SLA & $\mathbf{1}(1)$ & $\mathbf{1}(1)$ \\
$U$ & $\mathbf{2}(2)$ & $\mathbf{1 . 5}(1)$ \\
$V$ & $\mathbf{6}(4)$ & $\mathbf{5}(3)$ \\
Vorticity & $\mathbf{6}(5)$ & $\mathbf{5}(4)$ \\
\hline
\end{tabular}

SWOT + two nadir-observing system is slightly better than the performance of a four-satellite configuration.

\section{c. Impact of the residual roll error}

Because the amplitude of submesoscale features decreases as wavenumber increases, the potential of SWOT measurements strongly depends on the performance of measurement error reduction techniques. If longwave roll errors are not accurately reduced, it could impact mesoscale observation (i.e., wavelength $>100 \mathrm{~km}$ ). However, even when considering a pessimistic case of roll error reduction corrected with empirical cross calibration (Dibarboure et al. 2012a), surface gradients induced by residual signals are small when compared with SLA surface gradients. Even in the pessimistic case, the maximal along-swath gradient observed at swath extremities is near $3 \mathrm{~mm} / 10 \mathrm{~km}$, whereas the gradients induced by mesoscale and submesoscale signal can reach more than $30 \mathrm{~mm} / 10 \mathrm{~km}$.

Considering the long-wavelength fraction (i.e., wavelengths larger than $100 \mathrm{~km}$ ) of the reconstructed signal in the SWOT swath, even pessimistic residual roll errors have a small impact on errors for SLA and zonal velocity reconstruction, as shown in Table 4. Conversely, the main impact of a larger residual roll error on mesoscale reconstruction is on the meridional velocity and vorticity fields, with $+30 \%-50 \%$ reconstruction error.

Combining SWOT with nadir altimeters can contribute to reducing the roll impact: nearly a $1 \%$ reduction is observed for meridional velocities. Errors obtained in the SWOT swath, when combined with the J2EN constellation, are comparable to errors obtained with SWOT alone in its optimistic configuration. The simple multimission OI used in this paper thus has the ability to perform additional empirical SWOT cross calibration during the gridding process.

\section{Summary and conclusions}

This paper focused on SWOT's ability to replace or to complement altimetry for mesoscale applications, that 
is, for space and time scales larger than $100 \mathrm{~km}$ and 10 days, respectively. SWOT will provide an unprecedented sampling capability for the observation of surface mesoscale signals (sea level, $U, V$, and vorticity). SWOT's large swath samples will enable improvements in sea surface signal reconstruction in a large part of the ocean. Estimates show that, during a 5-day time period, sampling in swaths covers nearly $40 \%$ of the ocean's surface (for latitudes of $<70^{\circ}$ ). A 10-day sampling, equivalent to the current Jason-2 altimeter, will allow coverage of nearly $60 \%$ of the surface of the oceans. In contrast, in the same time interval, only $12 \%$ of the oceans are covered with the historical four-satellite constellation.

For mesoscale variability (100 km/10 days), the wide swath from SWOT provides a sampling capability equivalent to two-four nadir altimeters. This capability is spatially inhomogenous and depends on the orbit characteristics. At certain latitudes (e.g., $38^{\circ}$ ) the temporal sampling is optimal and the OSSE reconstruction error is small (i.e., near 3\% of signal variance for SLA and less than $10 \%$ for surface velocities), yet at certain atitudes (e.g., $45^{\circ}$ ) the temporal sampling is suboptimal and the reconstruction error from SWOT alone is increased by a factor of 2 . Adding two nadir datasets in the merging process can complement the temporal sampling from the SWOT orbit and helps to stabilize the reconstruction error. Merging SWOT with two altimeters flying along the Jason and Envisat tracks would provide multisatellite mesoscale observation that is slightly better than the best four-satellite configurations used in the past.

Benefits of SWOT measurements are unprecedented within the swath. Even in a pessimistic roll error configuration, SWOT would make it possible to reconstruct mesoscale signal with an error from near $1 \%$ of the signal variance (SLA) to only near $6 \%$ for surface velocities ( $V$ component). This corresponds to a reduction of error of near one-third to two-thirds when compared with the historical four-altimeter constellation. Merging SWOT with the historical twoaltimeter constellation showed that nadir altimeters can contribute to minimize residual roll errors on SWOT. The low errors observed within the swath are very encouraging. In addition to improving on foursatellite configurations, SWOT will also give us an unprecedented view of smaller-scale variability within the swath. The small- to submesoscale signal reconstruction will be addressed in a future study.

Acknowledgments. This study was conducted by IFREMER with CNES funding, as part as the TOSCA program. P. Klein is supported by CNRS, IFREMER, the French Agence Nationale pour la Recherche (Contract REDHOTS ANR-09-BLAN-0365-02) and CNES (Contracts DAR 48000005442010 and 4800000599 2011). High-resolution simulations used in this study were performed on the Earth Simulator (Yokohama, Japan) through a memorandum of understanding signed by IFREMER, CNRS, and JAMSTEC. We warmly thank both reviewers who contributed to greatly improve the manuscript.

\section{APPENDIX}

\section{Principle of Optimal Interpolation}

The objective is to determine the best estimation of the field $\theta(x)$ in a given position $x$ (space and time dependent), using the observations $\phi(i)$ unevenly distributed in space and time. The best least squares linear estimator $\theta_{\text {ext }}(x)$ is given by Bretherton et al. (1976) as

$$
\theta_{\text {ext }}(x)=\sum_{i=1}^{n} \sum_{j=1}^{n} A_{i j}^{-1} C_{x j} \phi_{\text {obs }}(i),
$$

where $\phi(i)$ includes the measurement errors $\varepsilon(i)$, here assumed to be uncorrelated with the signal:

$$
\phi_{\mathrm{obs}}(i)=\phi(i)+\varepsilon(i) .
$$

Here, $\mathbf{A}$ is the covariance matrix of the observations themselves and $\mathbf{C}$ is the covariance vector of the observations and the field to be estimated:

$$
\begin{aligned}
& A_{i j}=\left\langle\phi_{\text {obs }}(i) \phi_{\text {obs }}(j)\right\rangle=\langle\phi(i) \phi(j)\rangle+\langle\varepsilon(i) \varepsilon(j)\rangle \text { and } \\
& C_{x j}=\left\langle\theta_{x} \phi_{\text {obs }}(j)\right\rangle=\left\langle\theta_{x} \phi(j)\right\rangle .
\end{aligned}
$$

The space-time correlation function $C(r, t)$ used is expressed as follows, where $r$ and $t$ respectively represent space and time:

$C(r, t)=\left[1+a r+\frac{1}{6}(a r)^{2}-\frac{1}{6}(a r)^{3}\right] \exp (-a r) \exp \left(-t^{2} / T^{2}\right)$.

The space correlation radius (i.e., first zero crossing of $C$ ) $a$ and $e$-folding time scale $T$ used in the paper are respectively $100 \mathrm{~km}$ and 10 days.

\section{REFERENCES}

Alsdorf, D. E., E. Rodriguez, and D. P. Lettenmaier, 2007: Measuring surface water from space. Rev. Geophys., 45, RG2002, doi:10.1029/2006RG000197. 
Bretherton, F., R. Davis, and C. Fandry, 1976: A technique for objective analysis and design of oceanographic experiments applied to MODE-73. Deep-Sea Res., 23, 559-582.

Dibarboure, G., M.-I. Pujol, F. Briol, P. Y. Le Traon, G. Larnicol, N. Picot, F. Mertz, and M. Ablain, 2011: Jason-2 in DUACS: Updated system description, first tandem results and impact on processing and products. Mar. Geod., 34 (3-4), 214-241.

_ S. Labroue, M. Ablain, R. Fjørtoft, A. Mallet, J. Lambin, and J. C. Souyris, 2012a: Empirical cross-calibration of coherent SWOT errors using external references and the altimetry constellation. IEEE Trans. Geosci. Remote Sens., 50, 2325-2344.

— C. Renaudie, M.-I. Pujol, S. Labroue, and N. Picot, 2012b: A demonstration of the potential of Cryosat-2 to contribute to mesoscale observation. Adv. Space Res., doi:10.1016/j.asr. 2011.07.002, in press.

Ducet, N., P. Y. Le Traon, and G. Reverdin, 2000: Global high resolution mapping of ocean circulation from the combination of TOPEX/POSEIDON and ERS-1/2. J. Geophys. Res., 105, 19 477-19 498.

Durand, M., L. Fu, D. Lettenmaier, D. Alsdorf, E. Rodriguez, and D. Esteban-Fernandez, 2010: The Surface Water and Ocean Topography mission: Observing terrestrial surface water and oceanic submesoscale eddies. Proc. IEEE, 98, 766-779.

$\mathrm{Fu}$, L., and E. Rodriguez, 2004: High-resolution measurement of ocean surface topography by radar interferometry for oceanographic and geophysical applications. The State of the Planet: Frontiers and Challenges in Geophysics, IUGG Geophys. Monogr., Vol. 19, International Union of Geophysical Union, 209-224

Klein, P., B. L. Hua, G. Lapeyre, X. Capet, S. LeGentil, and H. Sasaki, 2008: Upper ocean dynamics from high 3-D resolution simulations. J. Phys. Oceanogr., 38, 1748-1763.

-, J. Isern-Fontanet, G. Lapeyre, G. Roullet, E. Danioux, B. Chapron, S. Le Gentil, and H. Sasaki, 2009: Diagnosis of vertical velocities in the upper ocean from high resolution sea surface height. Geophys. Res. Lett., 36, L12603, doi:10.1029/ 2009GL038359.

Le Traon, P. Y., and G. Dibarboure, 1999: Mesoscale mapping capabilities from multiple altimeter missions. J. Atmos. Oceanic Technol., 16, 1208-1223.

— future altimeter missions: The role of high-frequency signals. J. Atmos. Oceanic Technol., 19, 2077-2087.

_ - F. Nadal, and N. Ducet, 1998: An improved mapping method of multisatellite altimeter data. J. Atmos. Oceanic Technol., 15, 522-533.

—_, G. Dibarboure, and N. Ducet, 2001: Use of a high-resolution model to analyze the mapping capabilities of multiplealtimeter missions. J. Atmos. Oceanic Technol., 18, 1277-1288. , Y. Faugère, F. Hernandez, J. Dorandeu, F. Mertz, and M. Ablain, 2003: Can we merge GEOSAT Follow-On with
TOPEX/POSEIDON and ERS-2 for an improved description of the ocean circulation? J. Atmos. Oceanic Technol., 20, 889-895.

— P. Klein, B. L. Hua, and G. Dibarboure, 2008: Do altimeter wavenumber spectra agree with the interior or surface quasigeostrophic theory? J. Phys. Oceanogr., 38, 1137-1142.

Ollivier, A., 2006: Nouvelle approche pour l'extraction de paramètres géophysiques des mesures en altimétrie radar (New approaches for the extraction of geophysical parameters from radar-altimetry measurements). Ph.D. thesis, INPG, 192 pp. [Available online at http://tel.archives-ouvertes.fr/docs/00/20/ 44/75/PDF/ollivier.pdf.]

Pascual, A., Y. Faugère, G. Larnicol, and P.-Y. Le Traon, 2006: Improved description of the ocean mesoscale variability by combining four satellites altimeters. Geophys. Res. Lett., 33, L02611, doi:10.1029/2005GL024633.

- C. Boone, G. Larnicol, and P.-Y. Le Traon, 2009: On the quality of real-time altimeter gridded fields: Comparison with in situ data. J. Atmos. Oceanic Technol., 26, 556-569.

Pujol, I., and G. Larnicol, 2005: Mediterranean sea eddy kinetic energy variability from 11 years of altimetric data. J. Mar. Syst., 58 (3-4), 121-142.

Rodríguez, E., 2010: The Surface Water and Ocean Topography (SWOT) mission. Proc. of the Ocean Surface Topography Science Team (OSTST) Meeting, Lisbon, Portugal, AVISO, $61 \mathrm{pp}$. [Available online at http://www.aviso.oceanobs.com/ fileadmin/documents/OSTST/2010/oral/22_Friday/afternoon/ Rodriguez.pdf.]

Schlax, M. G., and D. B. Chelton, 1992: Frequency domain diagnostics for linear smoothers. J. Amer. Stat. Assoc., 87, 10701081.

Smith, W. H. F., and R. Scharroo, 2009: Mesoscale ocean dynamics observed by satellite altimeters in non-repeat orbits. Geophys. Res. Lett., 36, L06601, doi:10.1029/2008GL036530.

Tai, C. K., 2006: Aliasing of sea level sampled by a single exactrepeat altimetric satellite or a coordinated constellation of satellites: Analytic aliasing formulas. J. Atmos. Oceanic Technol., 23, 252-267.

Thibaut, P., J. C. Poisson, A. Ollivier, E. Bronner, and N. Picot, 2009a: Singular value decomposition applied on altimeter waveforms. Proc. Ocean Surface Topography Science Team (OSTST) Meeting, Seattle, WA, AVISO, 12 pp. [Available online at http://www.aviso.oceanobs.com/fileadmin/documents/ OSTST/2009/oral/Thibaut_SVD2.pdf.]

$\longrightarrow,-$, N. Tran, E. Bronner, and N. Picot, 2009b: Jason-2 instrumental and processing status. Proc. Ocean Surface Topography Science Team (OSTST) Meeting, Seattle, WA, AVISO, 17 pp. [Available online at http://www.aviso. oceanobs.com/fileadmin/documents/OSTST/2009/oral/Thibaut_ status.pdf.] 